\title{
Latest Results on LED Museum Lighting: Colour Quality and Artwork Preservation
}

\begin{abstract}
This paper describes a comprehensive study on museum lighting: one part of the study investigates the damage potential of LED museum lighting by generating composite LED spectra with the help of a mathematical algorithm, while the other part investigates the effects of LED lighting on the appearance of artworks. Spectral optimization of LED light has been carried out by using historical pigment reflectance samples instead of the test colour samples used in the CIE CRI method [CIE 1995], because the reflectance of these historic pigments is significantly different from the reflectance of today's pigments.
\end{abstract}

Keywords: museum lighting, colour rendering, damage potential.

\section{Introduction}

Display of art is a challenging field for lighting designers. In museums not only general lighting requirements should be fulfilled, but also many special issues should be addressed. Such special issue is to present the intention of the artist, to save the artwork from damage and to help the visitor to understand the artwork.

The European Commission is funding a three year research project entitled HI-LED [EU FP7 2014] (Human Centric Intelligent Light Engines for the uptake of SSL in Europe) which has the aim to develop SSL based light engines for advancing human alertness, horticulture and museum lighting. The task of the Virtual Environments and Imaging Technologies Research Laboratory is to find optimal lighting solutions for museums exhibiting artworks from different epochs of European art. Our research team started this research task based on its experiences from a previous research project (LED4ART) [EU FP7 2011], where the aim was to produce high quality SSL lighting for the Sistine Chapel.

In European Museums, there are thematic exhibitions from one of the European art periods, but most of the largest museum exhibits artwork from different epochs.

\section{Damage potential analysis of LED based museum lighting}

Many natural substances (especially organic materials, like pigments used in painting) are subject to degrade over time. This process greatly depends on the material itself and the environmental conditions (including the irradiation). In this analysis, we focused on the deterioration effect (more specifically, the photochemical action) caused by the spectral composition of the light source used for presenting artistic creations. Formulae and principles about damaging effects are based on the CIE 157:2004 technical report [CIE 2004].

A computer software had been developed, which is capable to optimize the spectrum of different spectral components by the use of a simulation model. The goal was to create a series of spectra for each simulated light source and compare their minimum achievable damage potential (DI - damage index) to conventional museum lighting solutions. Also the maximum achievable DI values were also presented in order to show how high damage is possible, if this aspect is not taken into account, while choosing a spectral composition setting in a multi channel LED luminaire for museum lighting. We used two types of test light sources: One was based on an existing 12 channel "HI-LED first prototype luminaire", and the other was a 31 channel theoretical source based on an existing 20 channel tuneable LED light source present in our laboratory extended with the missing LED spectra.

Minimum and maximum DI values were calculated for each composite spectra realized by the two luminaires in the $2000 \mathrm{~K}-6500 \mathrm{~K}$ CCT (Correlated Colour Temperature) interval, with the restriction on duv to be within the \pm 0.005 range, and minimum $\mathrm{Ra}$ (CIE General colour rendering index [CIE 1995]) of 80, 85 and 90 . We compared the damage potential of these luminaires to black body radiators (a close approximation of incandescent light sources) and daylight sources (CIE D series illuminants) at each CCT, and also to a standard $2856 \mathrm{~K}$ black body source with and without using a cut off filter at $400 \mathrm{~nm}$. Figure 1 shows generated spectra with minimum DI.

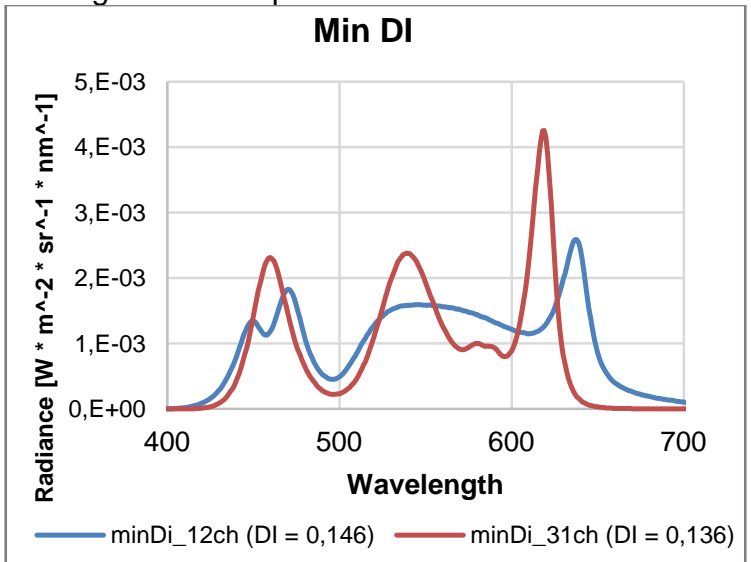

Figure 1. Optimized spectra for minimum and maximum CIE Damage Index by using a 12 channel or a 31 channel tuneable LED luminaire.

In worst case (using the $400 \mathrm{~nm}$ cut off filter and Ra above 90), the LED light sources perform $30 \%$ and $36 \%$ (the 12 or the 31 channel LED source respectively) better at $2856 \mathrm{~K}$ than the standard $2856 \mathrm{~K}$ black body source. Also, the CCT of the LED sources can be tuned up to $4300 \mathrm{~K}$ and $4700 \mathrm{~K}(12$ and 31 channel) to have less or equal DI than the standard $2856 \mathrm{~K}$ source. By increasing the minimally required $\mathrm{Ra}$ the minimum achievable $\mathrm{DI}$ increases only slightly, but that is insignificant in practical terms, 
which means that no compromise have to be made between colour rendering and damage potential while using properly selected LEDs for lighting solutions. Also the investigation of the gathered spectra showed, that LEDs placed in the $460 \mathrm{~nm}-620 \mathrm{~nm}$ range (in peak wavelength, which means $430 \mathrm{~nm}-660 \mathrm{~nm}$ effective range taking LED spectral bandwidth into account) is enough to achieve excellent colour rendering and low damage at the same time. This can be utilized during light source development and manufacturing.

\section{Effects of LED lighting on visual appearance of artworks}

Three real, painted pictures with artistic pigments were received (see Figure 2) from University of Fine Arts (Budapest), which had been used during the visual experiments.

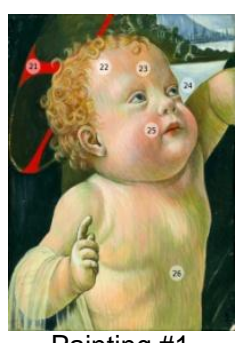

Painting \#1

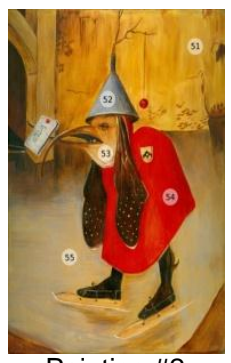

Painting \#2

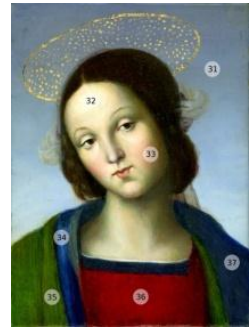

Painting \#3
Figure 2. Three paintings and the marked measuring points.

The paintings were presented in a darkened experimental room (Figure 3), where three special museum lighting luminaires (HI-LED prototype luminaires with 12 LED channels, see primary spectra in Figure 4) were installed in order to provide fully controllable illumination of the paintings.

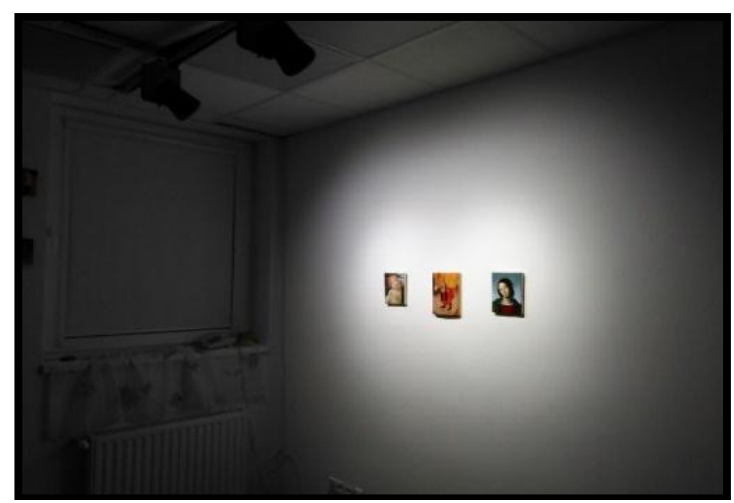

Figure 3. Experimental setup.

Two series of testing processes were carried out. In the first phase the effect of illuminance level and correlated colour temperature on the test persons' judgements had been investigated. During the second phase of the testing process the corresponding colour theory had been examined.

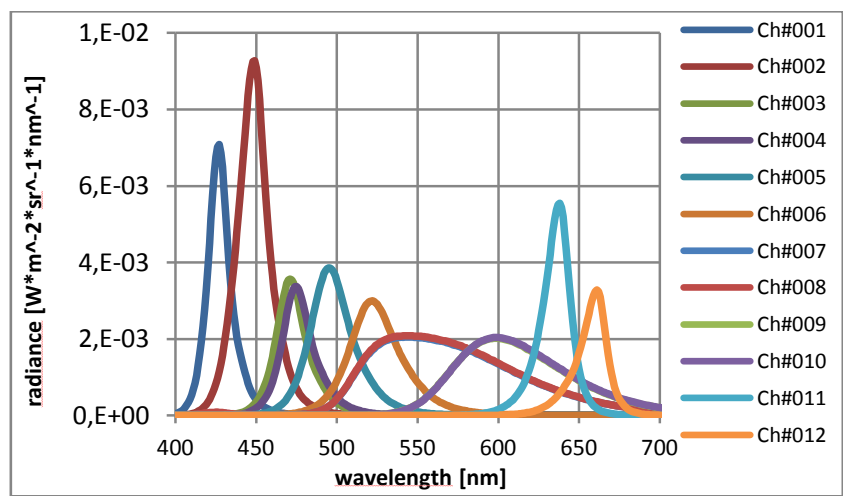

Figure 4. Primary channels of the HI-LED prototype luminaires.

Twelve test lights have been developed and the effect of illuminance level and correlated colour temperature on test persons' judgements has been investigated with the participation of 19 observers. Table 1 shows the measured lighting conditions at the start phase of the experiment. The experimental setup was designed at four CCTs $(2850 \mathrm{~K}, 4500 \mathrm{~K}, 5500 \mathrm{~K}$ and $6500 \mathrm{~K}$ ) and three illuminance levels (50 Ix, $100 \mathrm{Ix}, 200 \mathrm{Ix})$.

Table 1. Parameters of the twelve test lights.

\begin{tabular}{|c|c|c|c|c|c|}
\hline $\begin{array}{c}\text { Test } \\
\text { light } \\
\#\end{array}$ & $\begin{array}{c}\text { Target } \\
\text { illuminance } \\
{[\mathbf{I x}]}\end{array}$ & $\begin{array}{c}\text { Target } \\
\text { CCT }[\mathrm{K}]\end{array}$ & $\begin{array}{c}\text { Measured } \\
\text { illuminance } \\
{[\mathbf{I x}]}\end{array}$ & $d_{\mathrm{uv}}$ & $\begin{array}{c}C R I \\
R_{\mathrm{a}}\end{array}$ \\
\hline 1 & 50 & \multirow{3}{*}{2850} & 49.97 & 0 & 98 \\
\hline 2 & 100 & & 100.41 & -0.0004 & 98 \\
\hline 3 & 200 & & 199.23 & 0.0003 & 98 \\
\hline 4 & 50 & \multirow{3}{*}{4500} & 50.02 & 0.0008 & 99 \\
\hline 5 & 100 & & 99.48 & 0.0009 & 99 \\
\hline 6 & 200 & & 199.05 & 0.0003 & 99 \\
\hline 7 & 50 & \multirow{3}{*}{5500} & 49.55 & 0.0012 & 99 \\
\hline 8 & 100 & & 99.29 & 0.0013 & 99 \\
\hline 9 & 200 & & 198.92 & 0.0009 & 99 \\
\hline 10 & 50 & \multirow{3}{*}{6500} & 49.19 & 0.0013 & 99 \\
\hline 11 & 100 & & 99.29 & 0.0001 & 99 \\
\hline 12 & 200 & & 199.20 & 0.0008 & 99 \\
\hline
\end{tabular}

In the experimental room three observers at the same time observed the paintings from a distance of 2.5 meters from the pictures. The task of the observers was to scale their visual impression with the help of a questionnaire. The first part of the questionnaire (see Figure 5) contained six scales with contrary word pairs for evaluating each painting under the different test SPDs.

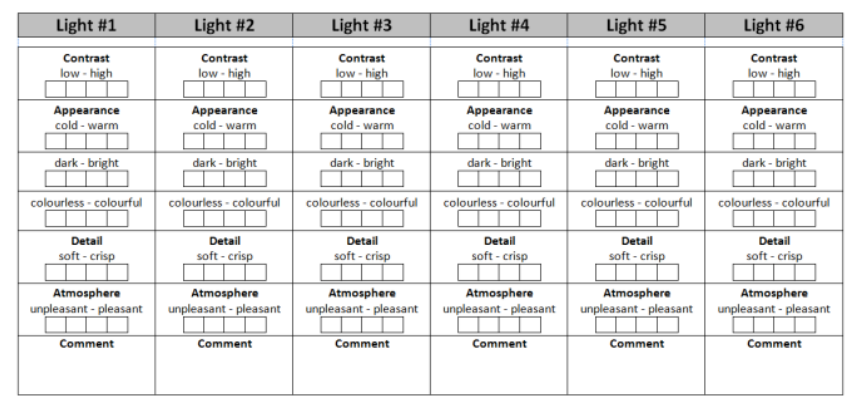

Figure 5. First part of the questionnaire.

Four of the scales were associated with appearance of the painting (low contrast - high contrast, cold - warm, dark - bright, pale - colourful) 
while two others were associated with atmosphere (soft - crisp details, unpleasant - pleasant). Each scale was evaluated by using a four-point categorical scale. The negative word was recorded with score values 1 or 2 . For example in case of answer 1 observer judged his/her visual experience significantly negative, in case of score value 2 the observer judged his/her experience slightly negative. In case of score values 3 or 4 the impression of the observer was slightly or very positive, respectively.

The second part of the questionnaire was (see Figure 6) related to the similarity of appearance under the test SPDs compared to the appearance under the natural (reference) light. The evaluation was also made on a four-point scale, where 1 meant that there is no similarity between the two scenarios, 2 meant that the two scenarios is slightly similar, 3 meant that the two scenarios are similar and 4 meant that they are identical.

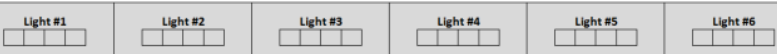

Figure 6 . Second part of the questionnaire.

The reference light was defined as the best spectral approximation of CIE D65 illuminant which could be realized by the HI-LED 12 channel prototype LED luminaire (having 10 different LED channels). This spectrum can be seen below together with CIE D65 illuminant (see Figure 7).

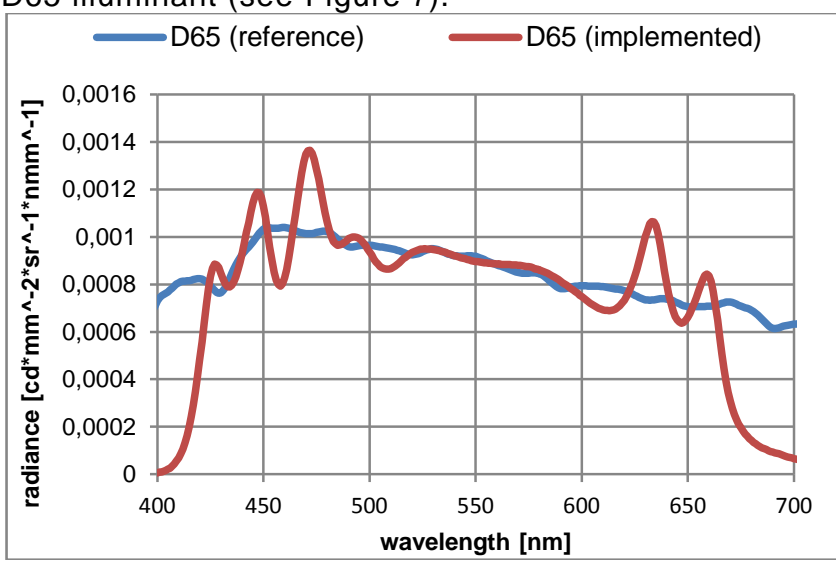

Figure 7. Approximation of CIE D65 illuminant with HI-LED prototype luminaire.

\section{Results}

Preferred illuminance level and Correlated Colour Temperature

Diagrams in Figure 8 show the impact of CCT and illuminance on observers' judgements for the six scales stressed by contrary word pairs. It can be seen that atmosphere is most pleasant in case of light with $5500 \mathrm{~K} \mathrm{CCT}$, but there is no significant difference among visual results at $4500 \mathrm{~K}-5500 \mathrm{~K}-6500 \mathrm{~K}$. The role of the illuminance level is less appreciable: atmosphere is more pleasant, when illuminance level is at least 100 lux, but there is no significant difference among 50 lux, 100 lux and 200 lux. Contrast is significantly higher than in case of $2850 \mathrm{~K}$, when CCT is at least $4500 \mathrm{~K}$. It can be seen that details are crisper when CCT increases and the appearance (clarity) is brighter when CCT increases as well. In most cases the role of the illuminance level is less, there is no significant difference among 50 lux, 100 lux and 200 lux.
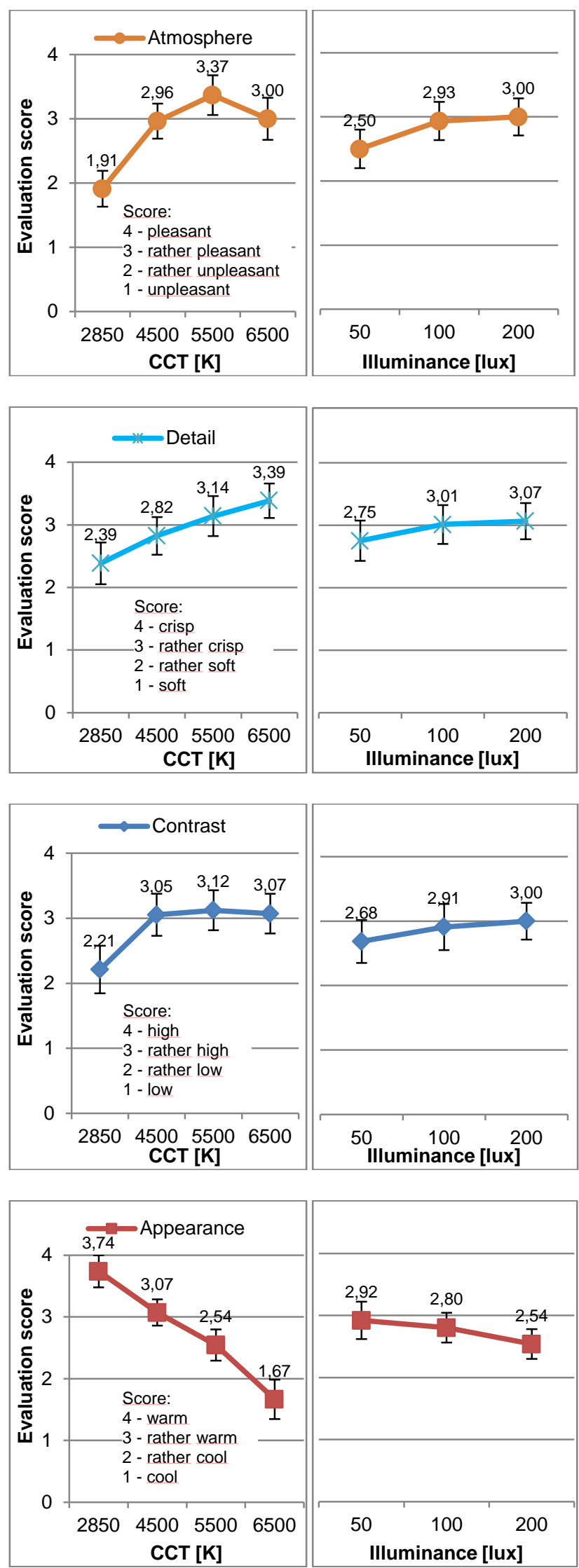

Figure 8. Impact of CCT and illuminance on observers' judgements for the six scales stressed by contrary word pairs.

\section{"Similar to daylight" appearance - testing "corresponding colour" theory \\ In the second phase of the experiment the corresponding colour theory [Schanda 2014] was}


investigated and further tests were carried out where the effect of the correlated colour temperature and illuminance level was investigated as well. These tests were performed with nine observers. The experimental setup was designed at three CCT values $(3500 \mathrm{~K}$, $4500 \mathrm{~K}$ and $5500 \mathrm{~K}$ ) and five illuminance levels (50 Ix, $100 \mathrm{~lx}, 200 \mathrm{~lx}, 400 \mathrm{~lx}$ and $600 \mathrm{~lx}$ ). Light trios were composed from these SPDs based on the following principle: the first light in each trio was the SPD with maximum $R_{a}$, the second (reference) light was the spectral approximation of CIE illuminant D65 and the third was the spectrum developed based on the corresponding colour theory.

Table 2 - Parameters of spectra used in light trios.

\begin{tabular}{|c|c|c|c|c|c|c|c|}
\cline { 2 - 8 } \multicolumn{1}{c|}{} & $\begin{array}{c}\text { MaxR }_{\mathrm{a}} \\
\mathbf{5 5 0 0 K}\end{array}$ & $\begin{array}{c}\text { MaxR }_{\mathrm{a}} \\
\mathbf{4 5 0 0 K}\end{array}$ & $\begin{array}{c}\mathbf{M a x R}_{\mathrm{a}} \\
\mathbf{3 5 0 0 K}\end{array}$ & $\begin{array}{c}\text { Correspon } \\
\text { ding 5500K }\end{array}$ & $\begin{array}{c}\text { Correspondin } \\
\mathbf{g} \text { 4500K }\end{array}$ & $\begin{array}{c}\text { Correspondin } \\
\mathbf{g} 3500 \mathrm{~K}\end{array}$ & D65 \\
\hline $\boldsymbol{x}$ & 0.3325 & 0.3611 & 0.4057 & 0.3307 & 0.3578 & 0.4010 & 0.3128 \\
$\boldsymbol{y}$ & 0.3432 & 0.3648 & 0.3912 & 0.3382 & 0.3613 & 0.3894 & 0.3292 \\
$\mathbf{C C T}[\mathrm{K}]$ & 5497 & 4498 & 3494 & 5576 & 4588 & 3586 & 6497 \\
$\boldsymbol{d}_{\mathrm{uv}}$ & 0.0010 & 0.0005 & 0.0001 & -0.0007 & 0.0000 & 0.0004 & 0.0032 \\
$\boldsymbol{R}_{\mathrm{a}}$ & 99.1 & 99.2 & 99.1 & 96.9 & 91.9 & 94.1 & 98.1 \\
$\boldsymbol{D} \boldsymbol{D}$ & 0.2083 & 0.1721 & 0.1447 & 0.2095 & 0.1824 & 0.1454 & 0.2138 \\
\hline
\end{tabular}

During the first part of the experiment the sufficient illuminance level for the illumination of paintings has been investigated in case of each CCT. Settings with maximum $R_{\mathrm{a}}$ can be seen in the first three columns of Table 2. The task of the observers was to decide which lighting level is ideal for the appearance of the paintings. CCT of test lights kept constant $(3500 \mathrm{~K}$, $4500 \mathrm{~K}$ or $5500 \mathrm{~K}$ ). Table 3 shows the questionnaire.

Table 3 - First part of the questionnaire, illuminance level.

\begin{tabular}{|c|c|c|c|c|c|c|c|c|c|c|c|c|c|c|}
\hline \multicolumn{5}{|c|}{$3500 \mathrm{~K}$} & \multicolumn{5}{|c|}{$4500 \mathrm{~K}$} & \multicolumn{5}{|c|}{$5500 \mathrm{~K}$} \\
\hline $\begin{array}{l}50 \\
1 \mathrm{x} \\
\end{array}$ & $\begin{array}{c}100 \\
1 \mathrm{x} \\
\end{array}$ & $\begin{array}{c}200 \\
1 \mathrm{x}\end{array}$ & $\begin{array}{c}400 \\
1 \mathrm{x}\end{array}$ & $\begin{array}{c}600 \\
1 \mathrm{x}\end{array}$ & $\begin{array}{l}50 \\
1 \mathrm{x}\end{array}$ & $\begin{array}{c}100 \\
1 \mathrm{x} \\
\end{array}$ & $\begin{array}{c}200 \\
\mathrm{Ix}\end{array}$ & $\begin{array}{c}400 \\
1 \mathrm{x}\end{array}$ & $\begin{array}{c}600 \\
1 \mathrm{x}\end{array}$ & $\begin{array}{l}50 \\
1 \mathrm{x}\end{array}$ & $\begin{array}{c}100 \\
1 \mathrm{x}\end{array}$ & $\begin{array}{c}200 \\
1 \mathrm{x}\end{array}$ & $\begin{array}{c}400 \\
1 \mathrm{x}\end{array}$ & $\begin{array}{c}600 \\
1 \mathrm{x}\end{array}$ \\
\hline & & & & & & & & & & & & & & \\
\hline
\end{tabular}

In the second part of the experiment the role of CCT had been investigated. Settings with maximum $R_{\mathrm{a}}$ were tested similarly to the first part of the experiment. The task of the observers was to decide that which CCT is ideal for the appearance of the paintings. Table 4 shows the used part of the questionnaire.

Table 4 - Second part of the questionnaire, CCT

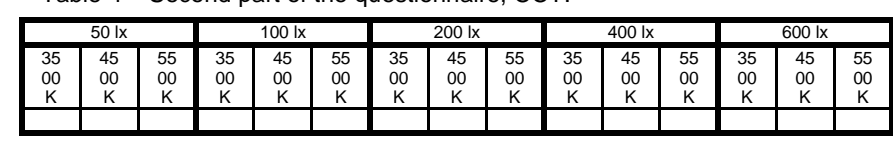

In the third part of the experiment the question of similarity has been investigated (see Table 5). Light trios have been created, that included those settings what the observers perceived as ideal in the first part of the experiment. l.e.: if the observer judged the $200 \mathrm{Ix}$ illuminance level appropriate in case of $3500 \mathrm{~K}$ series, then in the third part of the experiment the light trio containing the following settings was presented and they all had illuminance level of $200 \mathrm{Ix}$ :

- $3500 \mathrm{~K}-\mathrm{MaxR}_{\mathrm{a}}$,

- $\mathrm{D} 65$

- $3500 \mathrm{~K}$ - Corresponding Colour.
Table 5 - Third part questionnaire, similarity.

\begin{tabular}{|l|l|l|l|l|l|l|l|l|l|l|l|}
\hline \multicolumn{3}{|c|}{$1^{\text {st }}$ light trio } & \multicolumn{3}{c|}{$2^{\text {nd }}$ light trio } & \multicolumn{3}{c|}{$3^{\text {rd }}$ light trio } \\
\hline & & & & & & & & & & & \\
\hline
\end{tabular}

After the evaluation of the light trios the observers' task was the ranking of the three test lights according to their visual preference. When setting up the sequence the order may be equal between two light sources as well.

Table 6. Fourth part of the questionnaire, visual preference.

\begin{tabular}{|c|c|c|c|c|c|c|c|c|}
\hline \multicolumn{3}{|c|}{$1^{\text {st }}$ light trio } & \multicolumn{3}{|c|}{$2^{\text {nd }}$ light trio } & \multicolumn{3}{|c|}{$3^{\text {rd }}$ light trio } \\
\hline $\begin{array}{l}1 . \\
\max \\
R_{\mathrm{a}}\end{array}$ & $\begin{array}{l}2 . \\
\text { Ref. } \\
\text { D65 }\end{array}$ & $\begin{array}{l}3 . \\
\text { CC }\end{array}$ & $\begin{array}{l}1 . \\
\max \\
R_{\mathrm{a}}\end{array}$ & $\begin{array}{l}2 . \\
\text { Ref. } \\
\text { D65 }\end{array}$ & $\begin{array}{l}3 . \\
\mathrm{CC}\end{array}$ & $\begin{array}{l}1 . \\
\max \\
R_{\mathrm{a}}\end{array}$ & $\begin{array}{l}2 . \\
\text { Ref. } \\
\text { D65 }\end{array}$ & $\begin{array}{l}3 . \\
\text { CC }\end{array}$ \\
\hline & & & & & & & & \\
\hline
\end{tabular}

If the observer perceived $400 \mathrm{Ix}$ illuminance level appropriate in case of $4500 \mathrm{~K}$ series, then in the third part of the experiment the light trio with the following settings was presented (all with equal illumination level of 400 (x):

- $4500 \mathrm{~K}-\mathrm{MaxR}_{\mathrm{a}}$,

- D65,

- $4500 \mathrm{~K}$ - Corresponding Colour.

The CIE D65 setting was the reference illuminant in all cases and the observers' task was to rate the similarity of appearance in case of the other two test SPDs compared to the appearance under the natural (reference) illumination. Table 6 shows the questionnaire according to this part of the experiment.

The evaluation was also made on a four-point scale, where the value of 1 meant that the appearance of the paintings in case of the first light source is substantially similar to the appearance under the reference light source, the value of 2 meant that the appearance of the paintings in case of the first light source is similar to the appearance under the reference light source, the value of 3 meant that the appearance of the paintings in case of the second light source is similar to the appearance under the reference light source and the value of 4 meant that the appearance of the paintings in case of the second light source is substantially similar to the appearance under the reference light source.

\section{Corresponding colour theory investigations}

Based on the results (in case of $3500 \mathrm{~K}$ and $4500 \mathrm{~K}$ lighting), the appearance of the paintings showed more resemblance to the reference (under the D65 lighting), if the lighting spectrum was optimized according to the corresponding colour theory, and not based on the CRI.

In case of the CCT of $5500 \mathrm{~K}$ the appearance of the paintings is more similar under the setting which was developed based on the Maximum $R_{\mathrm{a}}$.

In the future, another series of visual experiments going to be planned to investigate further aspects of museum lighting, and corresponding colour theory will be investigated as well.

After the evaluation of the similarity the observers' task was to set the order of the three test light settings of the light trios according to their visual preference Figure 9 shows the order of the settings. It can be seen when the colour temperature was $3500 \mathrm{~K}$ the most preferred setting was the reference light (CIE illuminant D65) of the light trio. 


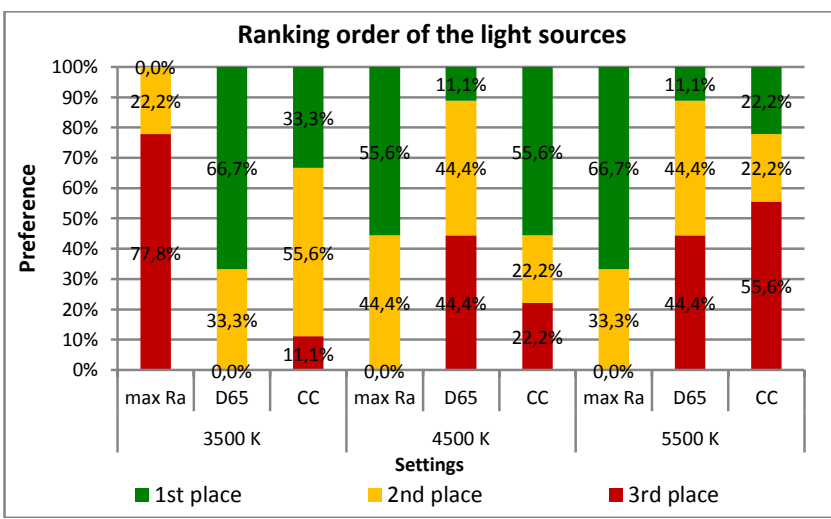

Figure 9. Ranking order of the test light sources.

This reference light is on the first place according to $66.7 \%$ of the participants. Based on the observers' judgement the spectrum developed based on the corresponding theory is more pleasant compared to the setting with maximum $R_{\mathrm{a}}$. The light source with $3500 \mathrm{~K}$ and with maximum $R_{a}$ was perceived as the worst setting in this section.

When the colour temperature was $4500 \mathrm{~K}$ then the setting with maximum $R_{\mathrm{a}}$ was judged as best. According to $55.6 \%$ of the observers' preference this setting is on the first place and none of the observer is placed it on the $3^{\text {rd }}$ place. The spectrum based on the corresponding colour theory is on the $2^{\text {nd }}$ place and CIE D65 illuminant is on the last place. More than $40 \%$ of the participants placed the CIE D65 setting on the last place.

In case of the CCT of $5500 \mathrm{~K}$ the most preferred spectra was the setting with maximum $R_{\mathrm{a}}$ and at least preferred was the setting developed based on the corresponding colour theory. More than $50 \%$ of the participants placed this spectrum on the $3^{\text {rd }}$ place.

\section{Conclusions}

Based on the observers' opinion the sufficient illuminance level for museum lighting is $200 \mathrm{~lx}$. More than $77 \%$ of the observers have judged this illuminance level as appropriate.

The most ideal correlated colour temperature for the most pleasant appearance of the paintings is $4500 \mathrm{~K}$ when the illuminance level is $50 \mathrm{~lx}, 100 \mathrm{~lx}$, $400 \mathrm{Ix}$ or $600 \mathrm{Ix}$. Based on our experiment when the illuminance level is $200 \mathrm{Ix}$ then the most ideal CCT is $3500 \mathrm{~K}$.

The appearance of the paintings rather under the corresponding colour spectrum is similar compared to the appearance under the reference light source in case of $3500 \mathrm{~K}$ and $4500 \mathrm{~K}$. When the correlated colour temperature is $5500 \mathrm{~K}$ then the appearance of the paintings is similar under the setting which is developed to have maximum $R_{\mathrm{a}}$.

The appearance of the paintings is more pleasant under the CIE D65 illuminant when the CCT is $3500 \mathrm{~K}$, while in case of $4500 \mathrm{~K}$ and $5500 \mathrm{~K}$ this reference D65 setting is perceived as the worst. This proves that the observers prefer the warm-white lights at least for museum lighting. In case of the correlated colour temperature of $4500 \mathrm{~K}$ and $5500 \mathrm{~K}$ the most pleasant appearance can be achieved by the setting which is developed to have maximum $R_{\mathrm{a}}$.

\section{Acknowledgement}

Authors would like to say thank you for the University of Fine Arts, Budapest for producing and borrowing test paintings for the experiments. The authors would like to express thanks for the financial support of the HI-LED EU FP7 project (grant number: 619912) in producing the above research.

\section{REFERENCES}

[1] CIE 1995, CIE 13.3-1995. Method of Measuring and Specifying Colour Rendering Properties of Light Sources. Vienna: CIE Central Bureau.

[2] CIE 2004, CIE TC 3-22 of Division 3 "Interior Environment and Lighting Design", "Control of damage to museum object by optical radiation (CIE 157:2004 Technical report)," International Commission on Illumination (CIE), 2004.

[3] Schanda 2014, J. Schanda, P. Csuti and F. Szabó, "A new concept of color fidelity form museum lighting.," LEUKOS: The Journal of the Illuminating Engineering Society of North America, 2014.

[4] EU FP7 2011, FP7 ICT-PSP project webpage: www.led4art.eu

[5] EU FP7 2013, EU FP7 ICT project webpage: www.hiled.eu

\section{Authors}

Authors: Dr. Ferenc Szabó, PhD., Department of Electrical Engineering and Information Systems, Faculty of Information Technology - University of Pannonia, 10. Egyetem str, 8200, Hungary, e-mail: szabof@szafeonline.hu

Peter Csuti, MSc., Department of Electrical Engineering and Information Systems, Faculty of Information Technology University of Pannonia, 10. Egyetem str, 8200, Hungary, e-mail: csuti.peter@virt.uni-pannon.hu 